\title{
A STRONG INHIBITOR OF CHYMOTRYPSIN/ELASTASE IS HIGHLY ANTIMETABOLIC TO HELICOVERPA ARMIGERA LARVAE
}

\author{
L.N. GATEHOUSE, J.T. CHRISTELLER, H.S GATEHOUSE \\ and X.Y. ZOU
}

Insect Science Group, Hort Research, Private Bag 11030, Palmerston North Corresponding author: lgatehouse@hortresearch.co.nz

\begin{abstract}
Chymostatin is a small non-protein poly-amino acid that specifically inhibits chymotrypsin-like enzymes by covalently binding to their active site. It is therefore a model for tight-binding proteinaceous protease inhibitors of chymotrypsin/elastase specificity. The Lepidopteran Helicoverpa armigera was raised on an artificial diet containing $0.03 \%$ chymostatin. After 14 days the experimental animals were approximately twentyfold smaller than the controls, although there was no increase in mortality. The RNA expression levels of the main trypsin gene group were found to decrease while that of the chymotrypsin/elastase gene group increased. Changes in activity of the midgut protease enzymes did not correlate to these changes in RNA expression.

Keywords: Helicoverpa armigera, chymostatin, RNA expression,
\end{abstract} protease inhibition.

\section{INTRODUCTION}

Helicoverpa armigera (Lepidoptera: Noctuidae) is a cosmopolitan pest of a broad range of plants from forestry to both agricultural and horticultural crop plants as well as a wide range of non crop species (Scott 1984). H. armigera larvae have the highly alkaline midgut characteristic of Lepidoptera and secrete serine proteases as their main gut endoproteinase activity (Terra \& Ferreira 1994). As generalist feeders, they are exposed to dietary protease inhibitors, ranging widely in both specificity and molecular structure, and hence might be expected to have evolved mechanisms to circumvent these defensive proteins (Broadway \& Villiani 1995).

We have previously shown (Gatehouse et al. 1997) that this insect has a large multigene family for serine proteinases which includes two main types, trypsin and chymotrypsin, on the basis of sequence homology, as well as divergent out-lying genes. Some divergent genes are expressed in midgut epithelium tissue (Bown et al 1997) at the RNA level but would not give rise to active enzymes and may be pseudogenes. Our previous work (Gatehouse et al. 1997) established that $H$. armigera larvae respond to the presence of protease inhibitors (PIs) in their diet by down-regulating, at the RNA level, expression of their main trypsin gene group and up-regulating their chymotrypsin gene group as well as the more divergent genes. This response was observed irrespective of the inhibitory specificity of the PI, although all the PIs tested were inhibitors of serine proteases. While Bown et al. (1997) also found a distinct group of PI up-regulated trypsin genes, we were unable to find these genes in our population of $H$. armigera despite extensive efforts. This may point to a substantial amount of genetic diversity between populations of H. armigera.

The most effective PI in terms of retardation of growth of the insects was bovine pancreatic trypsin inhibitor (BPTI) (Christeller et al. 2002), even though it inhibits only trypsins and not chymotrypsin-type proteases (Kunitz \& Northrop 1936). Other PIs tested have inhibited both activities to varying extents (J.T. Christeller, unpubl. data). The other 
distinguishing characteristics of BPTI are high stability due to its internal disulphide crosslinks (Kassell \& Laskowski 1965) and a higher binding constant (Gebhard et al. 1986). While the first point would suggest increased effectiveness as a PI due to better survival in the gut, some of the other PIs used were also internally disulphide crosslinked to various extents. The high binding constant to trypsin was considered significant and suggests that gene expression might be modulated solely through effects on trypsin activity.

The response of $H$. armigera larvae to a PI that has a high binding constant, a high stability and is a specific inhibitor of chymotrypsins is likely to be complex. If regulation of activity is through inhibition of trypsins, little effect on expression would be expected. However, since up-regulation of chymotrypsins is a clear defensive response to PI ingestion, direct inhibition of chymotrypsins should greatly retard development.

The non-protein polypeptide chymostatin (Umezawa et al. 1970) is a very strong and specific inhibitor of chymotrypsin and related enzymes. The mechanism of action is covalent binding to the active site of the enzyme. It is thus an excellent model for a stable proteinaceous PI of chymotrypsin/elastase specificity with a high binding constant. This paper reports the chronic use of chymostatin in artificial diet feeding assays and the long-term effects on growth. The effects on the expression of the main group trypsin and chymotrypsin genes were measured by enzyme assays and at the RNA level.

The work was also designed to provide further information on the mechanism of regulation of digestive proteases in insects. The expression of serine proteases in mammals is rapidly regulated by the free trypsin concentration via the monitor peptide feedback loop (Fushiki et al. 1989). Monitor peptide (MP), a homolog of BPTI, is co-secreted with the pancreatic enzymes into the gut where it binds to trypsin, in competition with dietary protein and any PIs, and is slowly cleaved by it. Free MP also binds to specific receptors in the gut wall that release of cholecystokinin which stimulates enzyme production, completing the feedback loop (Miyasaka et al. 1995). Other small proteins found in the mammalian gut also act similarly; luminal cholecystokinin releasing factor (Spannagel et al. 1996) and diazepam binding inhibitor (Herzig et al. 1996) are both potent cholecystokinin releasing factors. Long term (days to weeks) changes in the expression levels of the digestive protease genes in mammals are also known to occur independently to the rapid response on chronic exposure to PIs or from surgically induced pancreatitis (Carreira et al. 1996; Carreira \& Puigserver 1996).

Our previous work (Gatehouse et al. 1997) had shown that this insect differentially regulates the expression of its protease enzymes in response to chronic exposure to PIs and altered protein levels. In order to determine if a rapid regulation mechanism is operating we measured the response of the main group trypsin and chymotrypsin genes to short term perturbations of diet through addition of BPTI, chymostatin, increased protein or by feeding protein-free diets. A regulation mechanism similar to the monitor peptide feedback loop would predict a rapid (about 1 hour) response of the protease gene expression levels at the RNA level to the changes in the diet. Our data suggest that no rapid response mechanism is operating in $H$. armigera larval midgut and alternatives are discussed.

\section{MATERIALS AND METHODS}

Helicoverpa armigera neonate larvae were supplied from a line-bred, disease-free laboratory colony maintained at HortResearch, Auckland and originally field collected in Christchurch, New Zealand. The neonates were placed on variations of a standard artificial diet in $100 \mathrm{ml}$ medical specimen pottles ventilated with pinholes in the lids.

The high protein diet consisted of a base of $150 \mathrm{~g}$ lima bean flour, $80 \mathrm{~g}$ agar, $100 \mathrm{~g}$ brewers yeast, $120 \mathrm{~g}$ wheatgerm and 2 litres water. These ingredients were autoclaved and allowed to cool to $60^{\circ} \mathrm{C}$ before the following additions were made: $2 \mathrm{ml}$ linseed oil, $4 \mathrm{ml}$ wheatgerm oil, $20 \mathrm{~g}$ Vanderzant vitamin mix, $8 \mathrm{~g}$ ascorbic acid, $4 \mathrm{~g}$ nipagin, $2 \mathrm{~g}$ sorbic acid, $700 \mathrm{mg}$ penicillin, $700 \mathrm{mg}$ streptomycin, $40 \mathrm{mg}$ prochloraz and $500 \mathrm{ml}$ 
water to a final volume of 2.5 litres. The larvae were kept in a growth chamber maintained at $25 \pm 1{ }^{\circ} \mathrm{C}$. This high protein diet contains $3.5 \% \mathrm{w} / \mathrm{v}$ protein which gives optimal growth and survival, and contains no active PIs since those present are inactivated by autoclaving (McManus \& Burgess 1995). The control diet was the same as the high protein diet except that the components containing protein were present at one third concentration, i.e. the total protein concentration was $1.17 \% \mathrm{w} / \mathrm{v}$, with cellulose being substituted for the missing weight of ingredients. This lower level of protein was chosen as the effects of PIs are known to be greater on artificial diets where protein levels are suboptimal (Broadway \& Duffey 1986). The protein-free diet had all the protein containing components replaced with cellulose. The experimental diets were the control diet with the following additions: 1) $0.8 \%$ DMSO (chymostatin solvent), 2) $0.8 \%$ DMSO and $0.03 \%$ chymostatin (a concentration of equivalent molarity to the expression levels typically obtained for PIs in transgenic plants (Christeller et al. 2002) and 3) $0.3 \%$ BPTI. The control-DMSO diet was included since DMSO could affect the insects. All additions are expressed as percentages of wet weight, i.e. w/v.

The chronic feeding trials for growth response were conducted in three replicates of 12 larvae on each of control, DMSO and DMSO plus chymostatin diets. Larvae were individually weighed after 2, 4, 7,11 and 14 days. At 14 days, which is just before the normal time to pupation, larvae were sacrificed and their gut contents and midgut tissues isolated for enzyme assays and RNA preparation respectively. The gut contents of each larva were frozen in liquid nitrogen and stored at $-80^{\circ} \mathrm{C}$ until used. The frozen gut contents were ground in $0.1 \mathrm{M}$ Tris- $\mathrm{HCl} \mathrm{pH} 8.0$ and clarified by centrifugation. The supernatants were analysed for proteolytic activity with three substrates: leucine para-nitroanilide (LpNA), degraded by leucine aminopeptidase (LAP) a non-serine protease which is unaffected by chymostatin; N-succinyl-Ala-Ala-Pro-Leu para-nitroanilide (SAAPLPNA), a substrate for insect chymotrypsin/elastase, not hydrolysed by trypsin; and N-benzoylArg para-nitroanilide (BApNA), a trypsin substrate, not hydrolysed by chymotrypsin/ elastase (Christeller et al. 1992).

RNA was prepared and analysed for expression levels of the main protease gene groups as described previously (Gatehouse et al. 1997). Briefly, RNA was extracted using Trizol reagent (BRL, Gaithersburg, MD), quantitated by its 350-200 nm spectrum and used to prepare slot blots. These were hybridised to the inserts of pHtrypA6 and pHchyA4 for trypsin and chymotrypsin quantitation respectively with washing in $0.5 x$ SSC and $0.1 \%$ SDS at $60^{\circ} \mathrm{C}$. The probes were biotin-labelled by random priming and were detected using streptavidin-alkaline phosphatase and CDPstar reagent (Dupont NEN, Boston, MA). Blots were analysed by chemiluminescence detected on X-ray film and the developed films were quantitated with NIH Image software (Wayne Rasband, National Institutes of Health, USA). Statistical significance of results was determined by ANOVA.

The short term perturbation experiments were carried out using 4th instar larvae that had been grown from neonates on the control diet. They were fed control diet, high protein diet, protein-free diet, control DMSO diet, DMSO-chymostatin diet and BPTI diet. Larva were placed individually on a diet in pottles and at set intervals individual larva were dissected and midgut RNA prepared separately. Samples were taken after $30 \mathrm{~min}$, $1 \mathrm{~h}, 2 \mathrm{~h}, 4 \mathrm{~h}, 8 \mathrm{~h}, 24 \mathrm{~h}$ and $72 \mathrm{~h}$. The time of passage of diet through the gut for 4 th instar larvae on each diet was measured by moving additional larvae onto diet containing approximately $0.01 \%$ charcoal. RNA analyses were as described above.

\section{RESULTS AND DISCUSSION}

Following chronic ingestion for 14 days, there were no significant differences in survival on the various diets (data not shown) but weight gain was significantly affected $(\mathrm{P}<0.001)$ (Fig. 1). The DMSO diet was deleterious and the larvae were approximately half the weight of those on control diet at each time point. Larval weights on the DMSOchymostatin diet were dramatically lower at each time point and at the conclusion of the experiment were about 20 fold lower than the controls. All three treatments were significantly different from each other at all time points $(\mathrm{P}<0.001)$. 


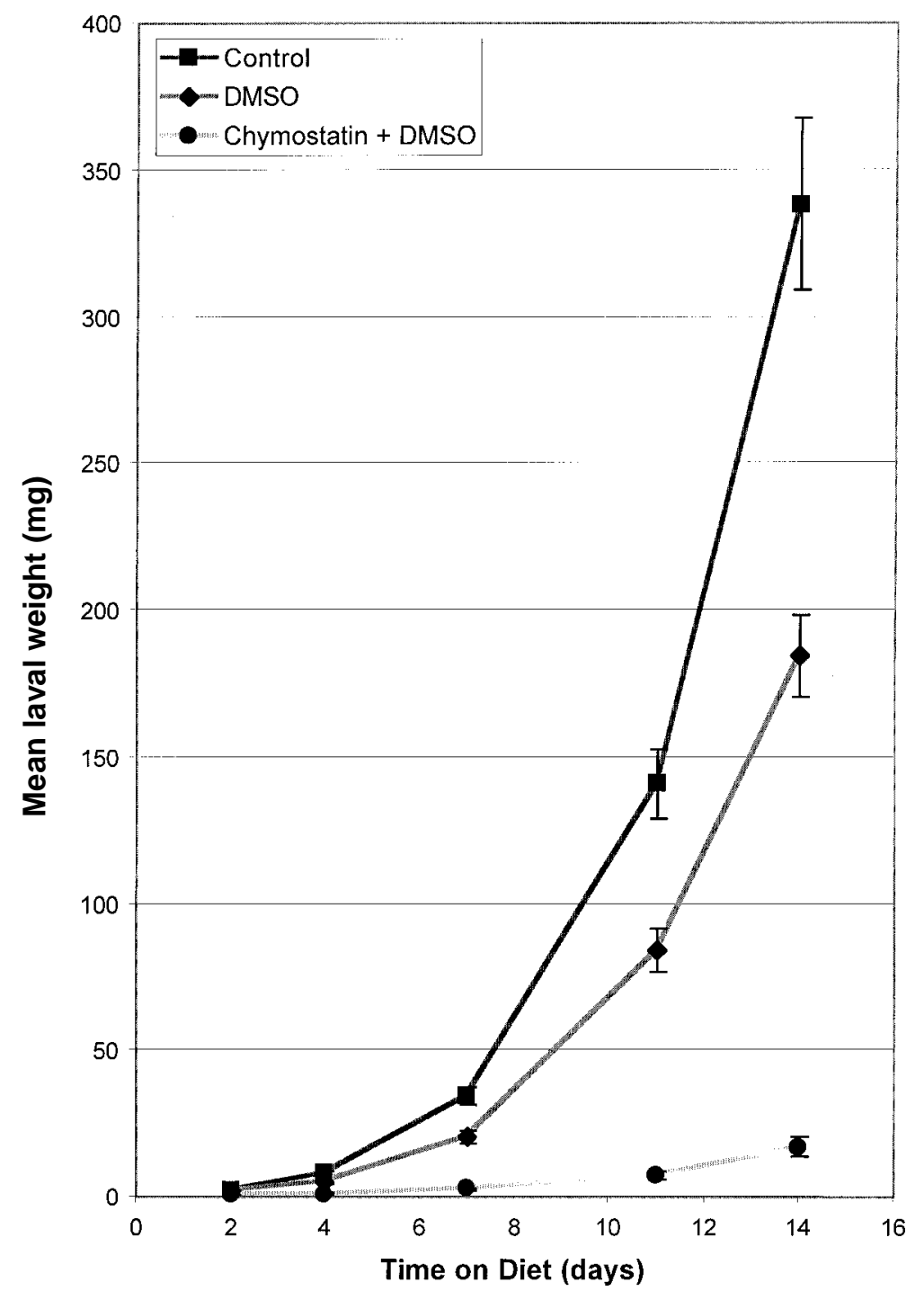

FIGURE 1: Weight gain of Helicoverpa armigera larvae on three artificial diets over 14 days. Standard error bars are shown.

Because the insect weights were very different, the gut enzyme activity results were normalised by plotting activity per $\mathrm{mg}$ fresh weight of insect (Fig. 2). There were significant differences in enzyme activity with each treatment $(\mathrm{P}<0.05)$. LpNA activity was lowest for control larvae, approximately doubled for larvae on the DMSO diet and approximately doubled again for larvae on the DMSO-chymostatin diet. Firstly, these results may reflect the different sizes of the insects and hence changes in the ratio of gut contents to gut wall. The surface area 


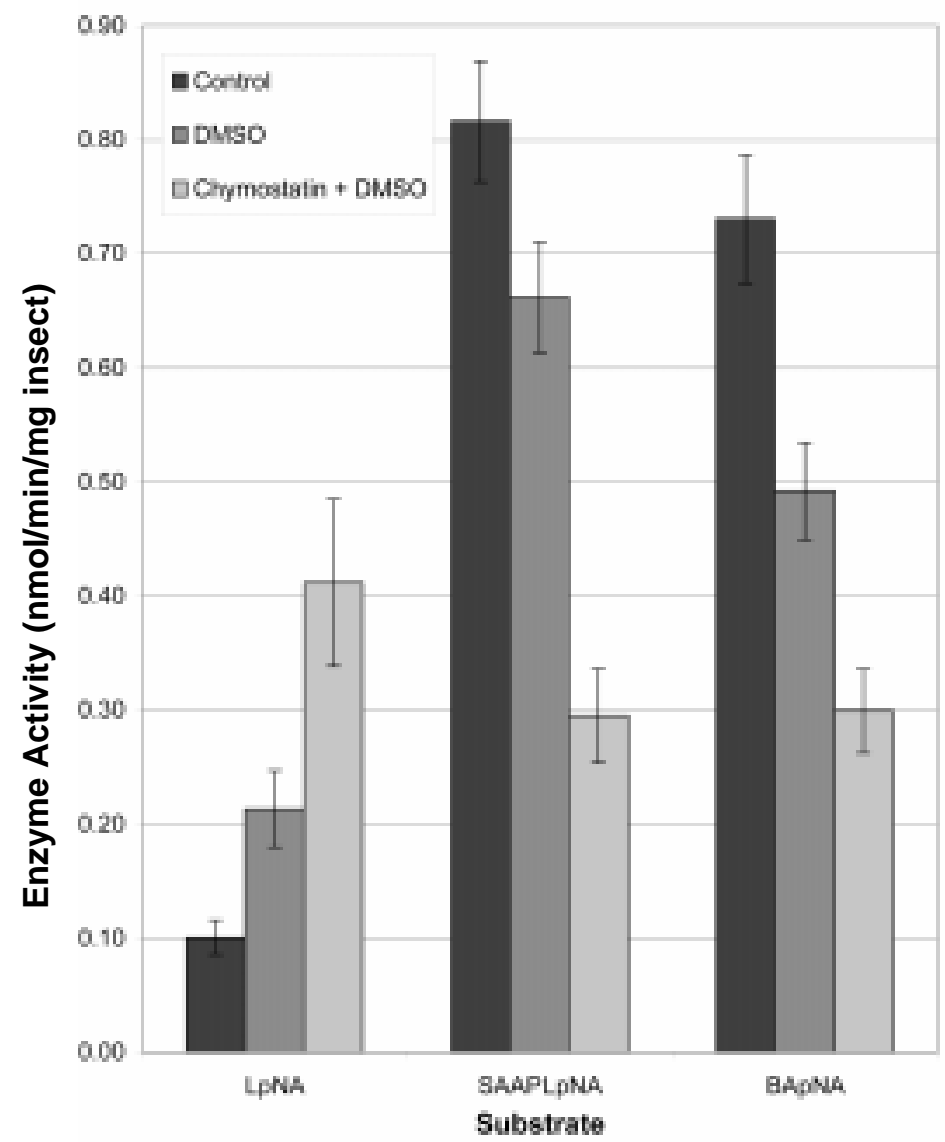

FIGURE 2: Protease enzyme activity ( $\mathrm{nmol} / \mathrm{min} / \mathrm{mg}$ insect) measured with three different substrates on midgut content preparations from larvae raised on three artificial diets. The bars represent standard error.

of a cylinder increases proportionally to its diameter but the volume increases with the square of its diameter. Thus small larvae have more gut surface relative to gut contents than large larvae and as LAP is a membrane associated/bound protein, more activity per weight of larva may be expected for small larvae. Secondly, DMSO may solubilise additional epithelial membrane components such as lipids and hence release more LAP into the gut contents than an aqueous diet would. The SAAPLpNA activities were highest for control larvae, slightly reduced for larvae on the DMSO diet, and strongly reduced for larvae on the DMSOchymostatin diet. These data strongly suggest a reduction in activity due to chymostatin in the diet since the control and DMSO diets were similar in activity. BApNA activities were highest for control larvae, reduced for larvae on the DMSO diet, and strongly reduced for larvae on the DMSO-chymostatin diet. These data show that any increase in trypsin activity, from undetected non-main group genes, which might compensate for loss of chymotrypsin activity in the chymostatin treatment is slight and is not significant. 


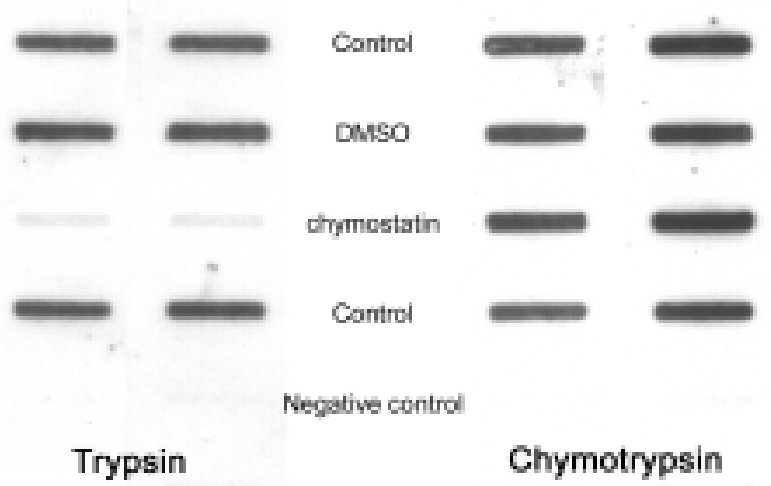

FIGURE 3: Slot blot analyses of midgut trypsin and chymotrypsin gene family mRNA expression following 14 days on three artificial diets. Duplicate slots are shown for each treatment.

The mRNA expression levels of the main trypsin and chymotrypsin/elastase groups of enzymes (Fig. 3) were not significantly changed by any of the treatments, except for trypsin mRNA levels following the chymostatin treatment, which were decreased to $7 \%$ of the controls $(\mathrm{P}<0.001)$, i.e. approximately 14 fold down-regulation. The mRNA expression level of the chymotrypsin/elastase gene group in the larvae reared on the chymostatin diet showed an increase to $115 \%$ of the controls but this was not significant. The DMSO diet showed smaller non-significant increases and the negative controls were barely detectable. These results are directly comparable to our earlier results (Gatehouse et al. 1997) where a trypsin-specific PI and non-specific serine protease PIs also caused a large decrease in mRNA level of the trypsin gene group and a small increase in the mRNA levels of the chymotrypsin/elastase gene group. Here we demonstrate an identical response to a specific chymotrypsin inhibitor.

Changes in measured enzyme activity may be due to direct inhibition of enzyme activities as well as changes in the enzyme expression levels in this complex multigene family. The levels of mRNA are a good indicator of enzyme expression although they do not measure any changes in translational or secretory activities. However, it is now clear that the effects on larval growth of inhibiting only the trypsins (Gatehouse et al. 1997), only the chymotrypsin/elastase midgut enzymes (this paper) or a combination of both activities (Gatehouse et al. 1997) are very similar. This supports an earlier suggestion (Christeller et al. 1992) that both trypsin and chymotrypsin/elastase activities are required for efficient protein digestion.

In other insect larvae, the response to PIs seems to be directed at turning off expression of the normal range of trypsin enzymes and producing a new range of trypsins which are not inhibited by most trypsin inhibitors (Jongsma et al. 1995). Because most plant PIs are much more effective trypsin inhibitors than chymotrypsin inhibitors, this is indeed a useful response. Helicoverpa armigera from our colony appear to lack the ability to up-regulate divergent trypsins and instead up-regulate chymotrypsin, although this resistance mechanism appears only partially effective. Thus, in our insect, chymostatin is indeed highly antimetabolic and a proteinaceous inhibitor with these properties would be a candidate insect resistance gene. This inhibitor would also be expected to be effective 
in insects which do exhibit trypsin-up-regulation since lepidopteran larvae seem to need both activities as shown in this paper and by Christeller et al. (1992).

In mammals, the monitor peptide regulation system produces rapid responses to dietary PIs, showing changes in transcription in time periods as short as $1 \mathrm{~h}$ (Fushiki et al. 1989). In order to see whether similar rapid response occurred in lepidopteran larvae, a series of short term perturbation experiments using diets with chymostatin, BPTI, 3-fold increased protein or protein-free were performed for up to 3 days. All versions of the diet passed through the gut of 4 th instar larvae in 2 to 3 hours. There were no significant differences in mRNA expression levels of the main trypsin or chymotrypsin gene groups between any of the diets (data not shown).

Thus the response in this insect to changes in protein concentration or the presence of PIs is slow and it lacks a mechanism for rapid regulation of digestive protease expression, be it a monitor peptide or other gut peptide (Fushiki et al. 1989; Spannagel et al. 1996; Herzig et al. 1996). This slow response is analogous to the long-term changes in gene expression seen in mammals chronically fed PIs or with surgically induced pancreatitis (Carreira et al. 1996). The slow response in mammals is regulated by dietary protein intake (Carreira \& Puigserver 1996), and Carreira et al. (1997) have shown that the mRNA stability of the mammalian pancreatic proteases were affected by dietary protein intake, but the details of this mechanism are unknown. The response we have observed here and previously (Gatehouse et al 1997), particularly where a reduction in protein concentration mimics the effects of addition of a PI to the diet, is consistent with such a mechanism.

The important observation reported here is the down-regulation of trypsin transcription by a chymotrypsin inhibitor, a mechanism previously only observed for trypsin inhibitors. This result rules out regulatory mechanisms based on sensing trypsin activity and indicates a mechanism based on sensing total midgut proteolytic activity or sensing dietary protein intake. This latter mechanism is consistent with the slow response to perturbations to the diet, the long term response to changes in dietary protein concentration (Gatehouse et al 1997) and the slow response seen in mammals (Carreira \& Puigserver 1996).

\section{ACKNOWLEDGMENTS}

Funding was provided by the NZ Foundation for Research, Science and Technology, HortResearch Contract C06X0001.

\section{REFERENCES}

Bown, D.P.; Wilkinson, H.S.; Gatehouse, J.A. 1997: Differentially regulated inhibitorsensitive and insensitive protease genes from the phytophagous insect pest, Helicoverpa armigera, are members of complex multigene families. Insect Biochem. Molec. Biol. 27: 625-638.

Broadway, R.M.; Duffey, S.S. 1986: Plant proteinase inhibitors: mechanism of action and effect on the growth and digestive physiology of larval Heliothis zea and Spodoptera exigua. J. Insect Physiol. 32: 827-833.

Broadway, R.M.; Villiani, M.G. 1995: Does host range influence susceptibility of herbivorous insects to non-host plant proteinase inhibitors? Entomol. Exp. Appl. 76: 303-312.

Carreira, S.; Fueri, C.; Chaix, J.-C.; Puigserver, A. 1996: Dietary modulation of the mRNA stability of trypsin isozymes and the two forms of secretory trypsin inhibitor in the rat pancreas. European J. Biochem. 239: 117-123.

Carreira, S.; Fueri, C.; Chaix, J.-C.; Puigserver, A. 1997: Stability of the mRNA encoding some pancreatic hydrolases is modulated by dietary protein intake in the rat. Brit. J. Nutr. 78: 833-843.

Carreira, S.; Puigserver, A. 1996: Correlated regulation of the mRNAs encoding secretory inhibitors and anionic trypsinogen $I$ in the rat pancreas depending on dietary intake. Nutr. Biochem. 7: 230-236. 
Christeller, J.T.; Burgess, E.P.J.; Mett, V.; Gatehouse, H.S.; Markwick, N.P.; Murray C.; Malone, L.A.; Wright, M.A.; Philip, B.A.; Watt, D.; Gatehouse L.N.; Lövei, G.L.; Shannon A.L.; Phung M.M.; Watson, L.M.; Laing, W.A. 2002: The expression of a mammalian proteinase inhibitor, bovine spleen trypsin inhibitor, in tobacco and its effects on Helicoverpa armigera larvae. Transgenic Res. (in press).

Christeller, J.T.; Laing, W.A.; Markwick, N.P.; Burgess, E.P.J. 1992: Midgut protease activities in 12 phytophagous lepidopteran larvae: dietary and protease inhibitor interactions. Insect Biochem. Molec. Biol. 22: 735-746.

Fushiki, T.; Kajiura, H.; Fukuoka, S.I.; Kido, K.; Semba, T.; Iwai, K. 1989: Evidence for an intraluminal mediator in rat pancreatic enzyme secretion: reconstitution of the pancreatic response with dietary protein, trypsin and the monitor peptide. J. Nutr. 119: 622-627.

Gatehouse, L.N.; Shannon, A.L.; Burgess, E.P.J.; Christeller, J.T. 1997: Characterization of major midgut proteinase cDNAs from Helicoverpa armigera larvae and changes in gene expression in response to four proteinase inhibitors in the diet. Insect Biochem. Molec. Biol. 27: 929-944.

Gebhard, W.; Tschesche, H.; Fritz, H. 1986: Biochemistry of aprotinin and aprotininlike inhibitors. In: Barrett, A.J.; Salvesen, G. ed. Proteinase Inhibitors. Elsevier Science, Amsterdam. Pp. 375-388.

Herzig, K.H.; Schon, I.; Tatemoto, K.; Ohe, Y.; Li, Y.; Folsch, U.R.; Owyang, C. 1996: Diazepam binding inhibitor is a potent cholecystokinin-releasing peptide in the intestine. Proc. Natl Acad. Sci. USA 93: 7927-7932.

Jongsma, M.A.; Bakker, P.L.; Peters, J.; Bosch, D.; Stiekema, W.J. 1995: Adaptation of Spodoptera exigua larvae to plant proteinase inhibitors by induction of gut proteinase activity insensitive to inhibition. Proc. Natl Acad. Sci. USA 92: 8041-5.

Kassell, B.; Laskowski, M. 1965: The basic inhibitor of bovine pancreas. V. The disulphide linkages. Biochem. Biophys. Res. Comm. 20: 463-468.

Kunitz, M.; Northrop, J.H. 1936: Isolation from beef pancreas of crystalline trypsinogen, trypsin, a trypsin inhibitor, and an inhibitor-trypsin compound. J. Gen. Physiol. 19: 991-1007.

McManus, M.T.; Burgess, E.P.J. 1995: Effects of the soybean (Kunitz) trypsin inhibitor on growth and digestive proteases of larvae of Spodoptera litura. J. Insect Physiol. 41: 731-738.

Miyasaka, K.; Funakoshi, A.; Nakamura, E.; Teraoka, H. 1995: Regulation of gene expression of pancreatic secretory trypsin inhibitor- 61 and -56 by bile and pancreatic juice in rats. Pancreas 11:246-255

Spannagel, A.W.; Guan, D.; Liddle, R.A.; Reeve, J.R. Jr.; Green, G.M. 1996: Purification and characterisation of a luminal cholecystokinin-releasing factor (LCRF) from rat intestinal secretion. Proc. Natl Acad. Sci. USA 93: 4415-4420.

Scott, R.R.ed. 1984. New Zealand pest and beneficial insects. Lincoln University College of Agriculture. Pp 113-4.

Terra, W.R.; Ferreira, C. 1994: Insect digestive enzymes: properties, compartmentalisation and function. Comp. Biochem. Physiol. 109B: 1-62

Umezawa, H.; Aoyagi, T.; Morishima, H.; Kunimoto, S.; Matsuzaki, M. 1970: Chymostatin, a new chymotrypsin inhibitor produced by actinomycetes. J. Antibiot. (Tokyo). 23: 425-7. 